\title{
Erratum to: Haemodynamic responses to dehydration in the resting and exercising human leg
}

\author{
James Pearson • Kameljit K. Kalsi • \\ Eric J. Stöhr • David A. Low · Horace Barker • \\ Leena Ali · José González-Alonso
}

Published online: 19 June 2013

(c) Springer-Verlag Berlin Heidelberg 2013

\section{Erratum to: Eur J Appl Physiol (2013) 113:1499-1509 DOI 10.1007/s00421-012-2579-2}

In the originally published article systemic $\mathrm{O}_{2}$ delivery values reported in Fig. 3 are incorrect. The correct calculation for systemic $\mathrm{O}_{2}$ delivery $\left(\mathrm{L} \mathrm{min}{ }^{-1}\right)=$ arterial $\mathrm{O}_{2}$ content $\left(\mathrm{mL} \mathrm{L}^{-1}\right) *$ cardiac output $\left(\mathrm{L} \mathrm{min}^{-1}\right)$. The error in the manuscript was due to a miscalculation in the unit conversion from $\mathrm{mL}$ to $\mathrm{L}$ resulting in an erroneously high systemic $\mathrm{O}_{2}$ delivery across all conditions of dehydration/ rehydration and rest and exercise. Therefore, this error does not change the statistical results, the interpretation of the results nor the implication of the findings. The recalculations for each condition are as follows, control rest $=1.16 \pm 0.06 \mathrm{~L} \mathrm{~min}^{-1}$, control exercise $=1.52 \pm$ $0.07 \mathrm{~L} \mathrm{~min}^{-1}, \quad 2 \%$ dehydration rest $=1.23 \pm 0.03 \mathrm{~L}$ $\min ^{-1}, 2 \%$ dehydration exercise $=1.58 \pm 0.07 \mathrm{~L} \mathrm{~min}^{-1}$, $3.5 \%$ dehydration rest $=1.37 \pm 0.07 \mathrm{~L} \mathrm{~min}^{-1}, 3.5 \%$ dehydration exercise $=1.69 \pm 0.06 \mathrm{~L} \mathrm{~min}^{-1}$, rehydration rest $=1.29 \pm 0.04 \mathrm{~L} \mathrm{~min}^{-1}$, rehydration exercise $=1.58$ $\pm 0.05 \mathrm{~L} \mathrm{~min}^{-1}$. Accordingly, the systemic $\mathrm{O}_{2}$ delivery panel from Fig. 3 has also changed.

The online version of the original article can be found under doi:10.1007/s00421-012-2579-2.

J. Pearson · K. K. Kalsi · E. J. Stöhr · D. A. Low

J. González-Alonso ( $\square)$

Centre for Sports Medicine and Human Performance,

Brunel University, Uxbridge, Middlesex UB8 3PH, UK

e-mail: j.gonzalez-alonso@brunel.ac.uk

Present Address:

J. Pearson

School of Health Sciences, Cardiff Metropolitan University,

Llandaff Campus, Western Avenue, Cardiff CF5 2YB, UK

Present Address:

E. J. Stöhr

Cardiff School of Sport, Cardiff Metropolitan University,

Cyncoed Campus, Cyncoed Road, Cardiff CF23 6XD, UK

Present Address:

D. A. Low

Neurovascular and Autonomic Medicine Unit, Clinical

Neurosciences, Faculty of Medicine, St. Mary's Hospital,

Imperial College London, London W2 1NY, UK

H. Barker · L. Ali

Department of Anaesthetics, Ealing Hospital,

NHS Trust, Southall, Middlesex, UK 
Fig. 3 Leg haemodynamics, $\mathrm{O}_{2}$ delivery and oxygen consumption with dehydration and rehydration Data are mean \pm SEM for seven participants. Asterisks different from control, hashes different from $2 \%$ dehydration, daggers different from $3.5 \%$

dehydration. Significance was accepted at $P<0.05$ and refers to differences in the respective conditions, i.e., either rest or exercise
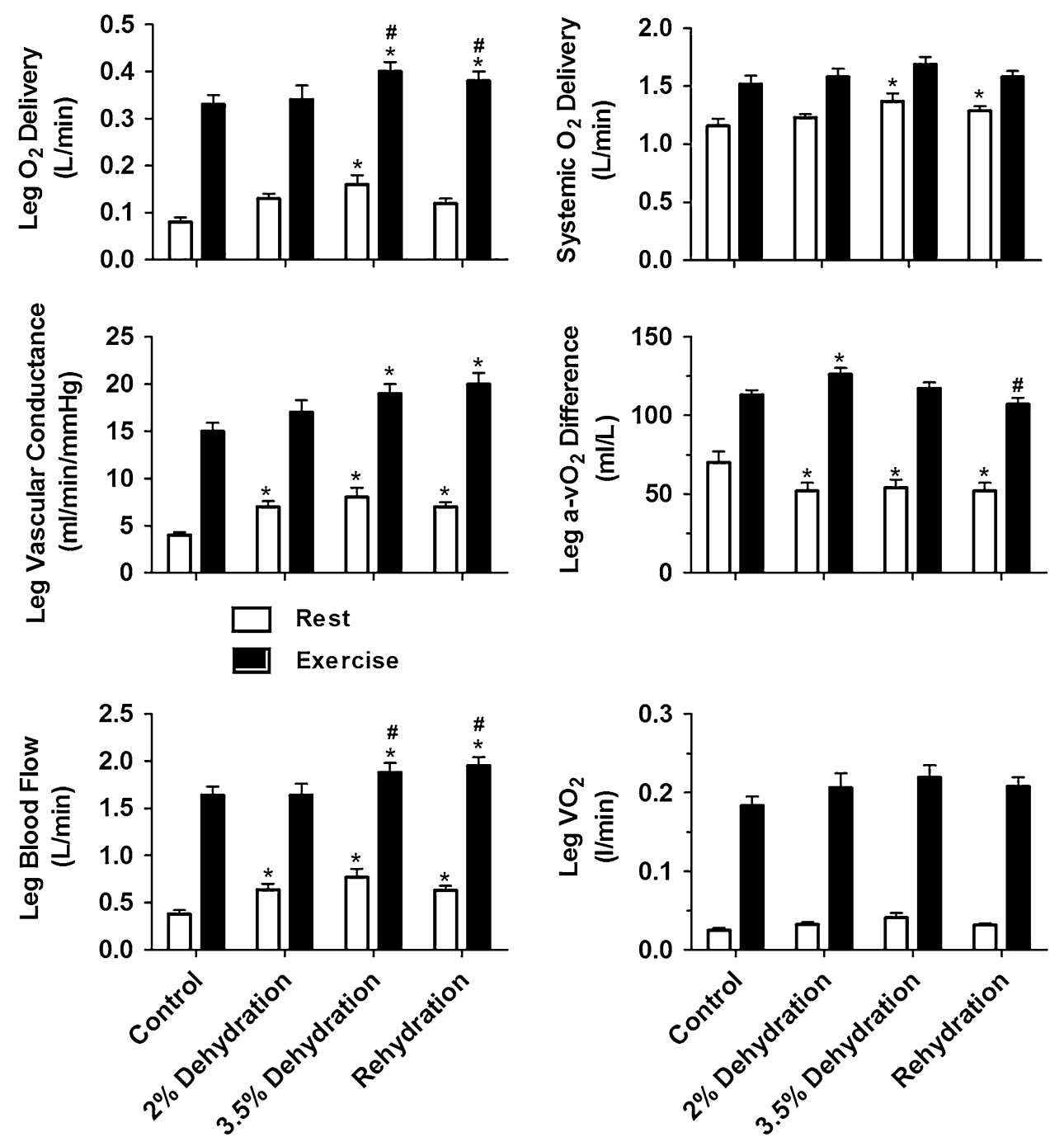